\title{
Metastatic Malignant Neoplasm in the Axilla
}

National Cancer Institute

\section{Source}

National Cancer Institute. Metastatic Malignant Neoplasm in the Axilla. NCI Thesaurus.

Code C35748.

A malignant neoplasm that has spread to the structures of the axilla from another anatomic site. 